\title{
The validity and significance of hormone levels in gynaecology
}

\author{
IAN F. SOMMERVILLE \\ M.D., Ph.D. \\ Institute of Obstetrics and Gynaecology, University of London
}

\begin{abstract}
Summary
The development of radioimmunoassay of steroid hormones in peripheral venous blood has led to a more direct index of gonadal production and concurrent monitoring of glandular function. While serial analyses of total urinary oestrogens can be correlated with luteinizing hormone (LH) excretion in treating amenorrhoea, radioimmunoassay of plasma oestrogens measures acute changes in ovarian responsiveness. For studies of androgens radioimmunoassay of plasma testosterone is the method of choice, but fractionation of urinary 17-oxosteroids may be useful and can be extended to include the pregnane series and corticoids. Urinary pregnanediol, however, may not reflect the endogenous secretion of progesterone and should be reserved for assessing induction of ovulation. Luteal function can be evaluated rapidly and specifically by radioimmunoassay of plasma progesterone. Although radioimmunoassay offers a new approach to ovarian physiology, its systematic application to disease is still in the future.
\end{abstract}

DURING recent years the development of ultrasensitive methods for the determination of steroids in biological fluids has led to two major advances in the clinical application of hormone assays. First, the direct determination of low concentrations of the natural hormones in peripheral venous blood has led to more valid indices of gonadal hormone production. Secondly, the rapidity of modern techniques permits concurrent rather than retrospective monitoring of glandular function. To cite but one example, the choice of the quantity of gonadotrophin used for the induction of ovulation can now be based upon results obtained on the same day that the sample is taken and this minimizes the risk of hyperstimulation and of multiple pregnancy.

This paper is not a review of the vast literature but will be limited to a practical consideration of modern attempts to assess the endogenous production of steroid hormones. The most direct approach is to calculate the blood production rate of hormone in terms of the mean plasma concentration and the metabolic clearance rate of isotopically labelled hormone. Subsequently, the secretion rate of hormone can be calculated from the production rate with a knowledge of peripheral transformations. Thus, the blood production rate of testosterone in healthy women has been calculated to be $0.34 \mathrm{mg} /$ day and, since approximately $0.20 \mathrm{mg}$ is derived from androstenedione, the secretion rate of the hormone is approximately $0.14 \mathrm{mg} /$ day (Tait and Horton, 1966).

Examples of secretion rates in healthy men and women are shown in Fig. 1. These values represent the current concept of the secretion of these hormones in quantitative terms and are in sharp contrast with some of the parameters used in the past. Thus, whereas there is a major overlap in the range of urinary total 17-oxosteroid excretion between men and women, it will be noted that the secretion rate of testosterone is more than fifty-fold greater in men than in women. However, the calculation of secretion rates involving the administration of more than one labelled steroid is not a practical approach for clinical work and, even if very low amounts of radioactivity are administered, the advisability of giving radioactive steroids to women who may subsequently become pregnant may be questioned. Accordingly, we must consider less complicated ways of obtaining similar information.

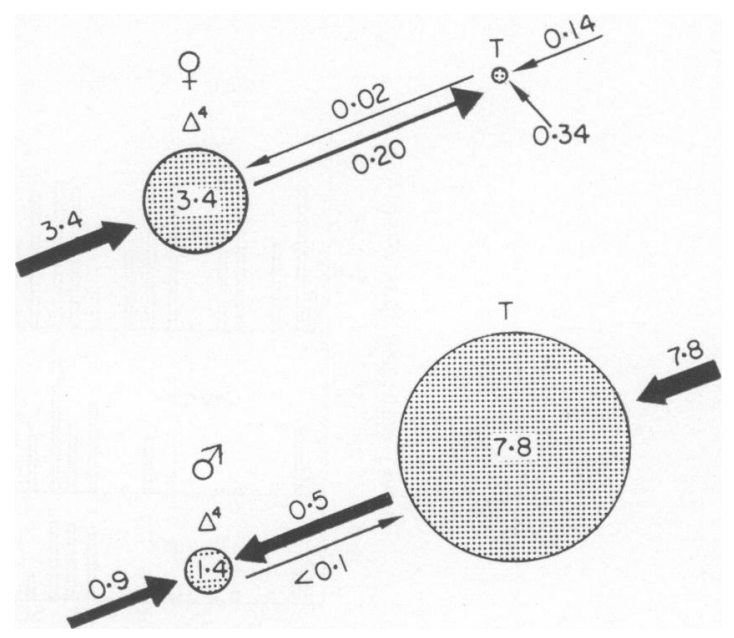

FIG. 1. Androgen secretion rates (mg/day): a schematic representation of the results of Tait \& Horton (1966). 
Indices of oestrogen production in women can be summarized as follows: (1) bioassay; (2) vaginal cytology; (3) urinary oestrogen determination; (4) plasma oestrogen determination; (5) metabolic clearance rate, production and secretion rates.

Bioassay is complicated and expensive and its use is mainly limited to pharmacological studies.

Vaginal cytology when carried out as serial tests may yield useful information-as in monitoring the effect of therapy but the results can also be misleading and are qualitative rather than quantitative.

By far the most established approach is a determination of the total urinary oestrogens (oestrone, oestradiol-17 $\beta$ and oestriol) although it must be remembered that there are numerous other oestrogens in urine. With regard to this test is should be emphasized that little is to be learned from an isolated determination, and serial analyses are essential. The typical biphasic excretory pattern of the ovulatory menstrual cycle is shown in Fig. 2 and the variation which can occur from day to day in the same post-menopausal woman, in Fig. 3. A useful chemical application involves a correlation between the excretion of $\mathrm{LH}$ and total oestrogens in selecting appropriate therapy in infertile women with established amenorrhoea. Values for urinary LH in normal cycles are shown in Fig. 4.

In view of the spectrum of oestrogen metabolites, an attractive alternative is the determination of oestradiol, oestrone or one of the oestriols in peripheral venous blood and results obtained by a radio- immunoassay (Emment, Collins and Sommerville, 1972) are summarized in Table 1. Plasma analysis has the advantage that acute changes can be observed, for example, the oestrogen surge which may coincide with or precede the LH peak or acute changes in dynamic tests, e.g. in assessing the responsivity of the ovary to gonadotrophin therapy (Fig. 5). On the other hand, plasma oestrogen analyses have the disadvantage that there may be random or nycterohemeral changes from hour to hour although these

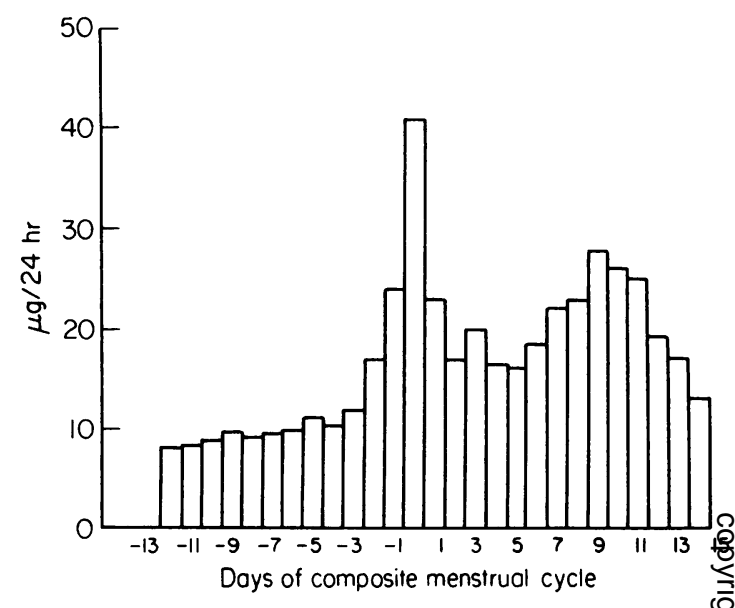

Fig. 2. Total urinary oestrogen excretion. Mean levels obtained from eleven normal menstrual cycles.
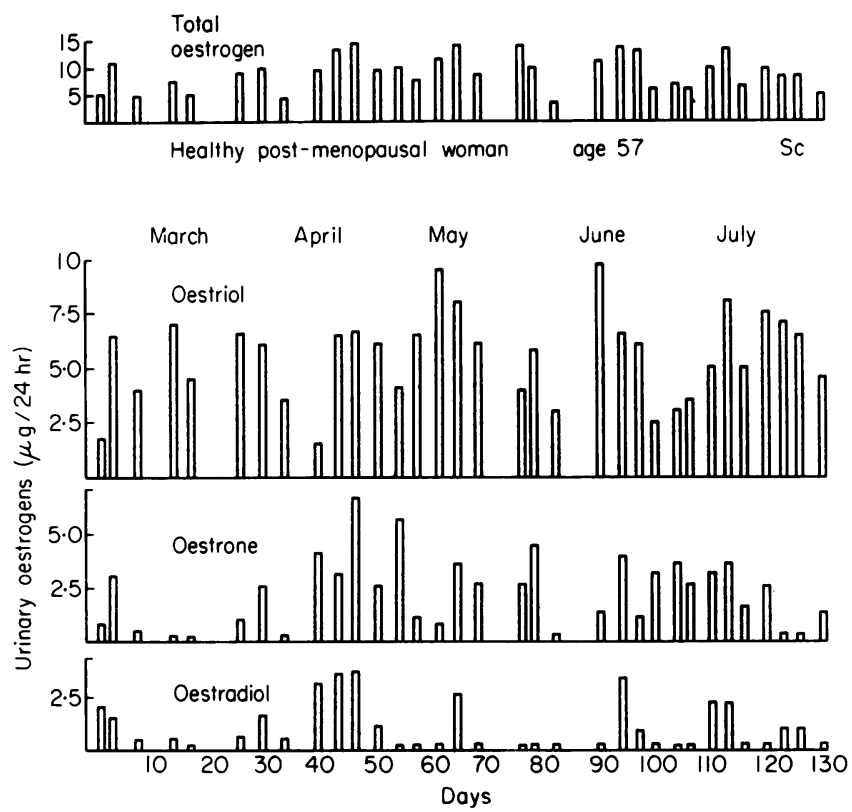

FIG. 3. Day-to-day variations in the urinary excretion of total and fractionated oestrogens in a post-menopausal woman. 
TABLE 1. The mean and range of values for oestrone and oestradiol in peripheral venous plasma from groups of healthy men and women

\begin{tabular}{lccccc}
\hline & \multicolumn{3}{c}{ Oestrogen pg/ml plasma } \\
\cline { 2 - 3 } & \multicolumn{2}{c}{ Oestrone } & & \multicolumn{2}{c}{ Oestradiol } \\
\cline { 2 - 3 } \cline { 5 - 6 } & Mean & Range & & Mean & Range \\
\hline Men & 48 & $29-75$ & & 28 & $13-46$ \\
Women & 117 & $45-210$ & & 64 & $18-214$ \\
*Days 1-10 & 162 & $75-240$ & & 161 & $53-340$ \\
$\quad 11-18$ & 156 & $96-209$ & & 132 & $26-242$ \\
Post-menopausal & 32 & $13-56$ & & 15 & $<10-36$ \\
\hline
\end{tabular}

* Day 1 = first day of menses.

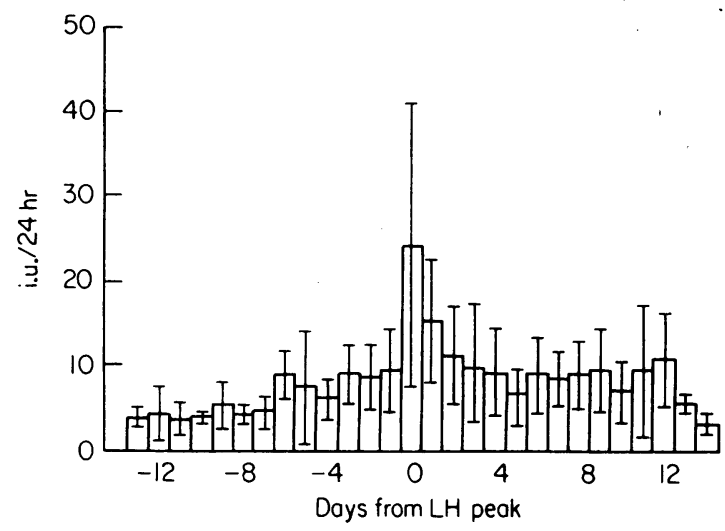

FIG. 4. The levels of urinary LH (mean \pm s.d.) in seven subjects (cycle 1).

do not appear to be major in either non-pregnant women (Fig. 6) or during pregnancy.

The study of androgen production in women is complicated by several factors-notably the low concentrations of androgens in blood and tissues, the transformation of androgens to oestrogen and the extent to which androgenic activity may depend upon conversion to other products. Methods which have been used for the assessment of androgen production in women include: (1) bioassay; (2) urinary 17-oxosteroids (total or fractionated); (3) urinary testosterone glucuronoside; (4) plasma testosterone and other $\mathrm{C}_{19}$-steroids; (5) metabolic clearance, blood production and interconversion rates; (6) $5 \alpha$-reductase activity in growth-responsive tissues.

Bioassay had the obvious advantage that biologically active androgen was determined but proved too complex for clinical application.

The determination of total neutral 17-oxosteroids has serious limitations as an index owing to the fact that this group of compounds is mainly derived from non-androgenic or weakly androgenic precursors and that the principal androgen-testosterone-is not a 17-oxosteroid. On the other hand, useful
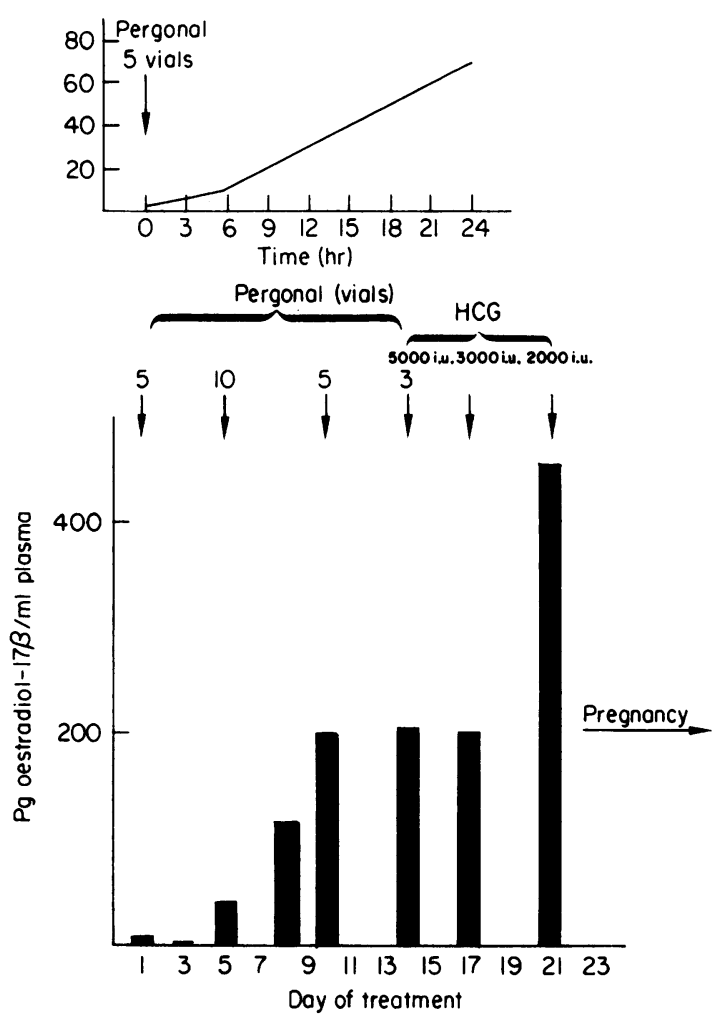

FIG. 5. Monitoring the effect of ovarian stimulation by plasma oestradiol determinations.

information can be obtained by the determination of individual 17-oxosteroids and this approach has been extended to the determination of numerous neutral steroids including compounds of the preg. nane series and corticoids (Ros and Sommerville, 1971). An example of one of these steroid profiles using high resolution glass capillary columns is shown in Fig. 7, and the results throughout a menstrual cycle are shown in Fig. 8. 


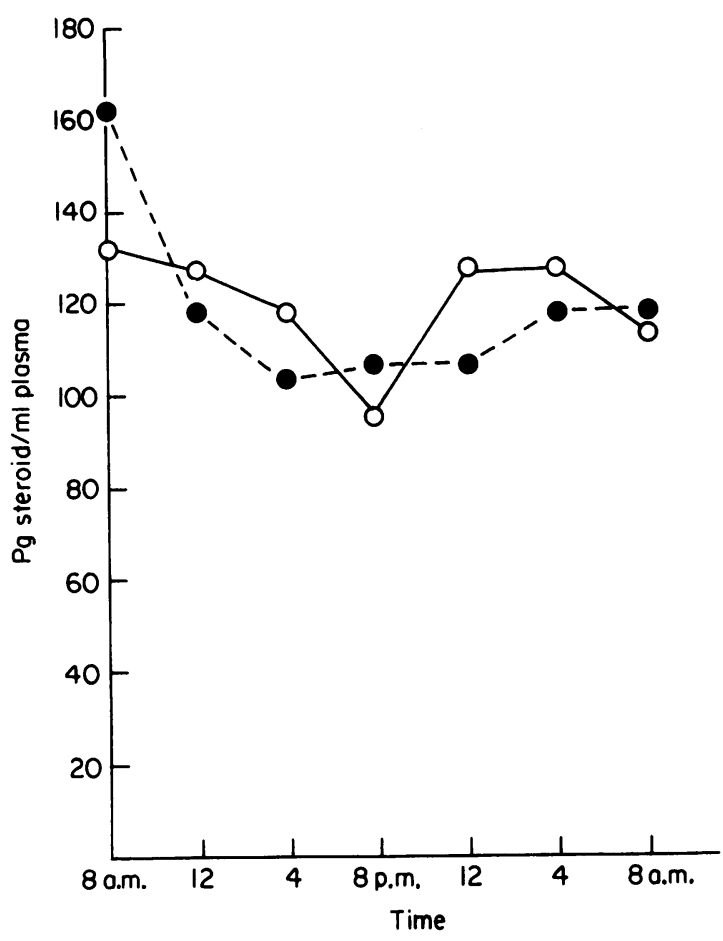

Fig. 6. The nycterohemeral variation of oestrone and oestradiol in peripheral venous plasma from a healthy woman on days 22 and 23 of her cycle. $\bigcirc-O$, Oestradiol.--0 , oestrone.

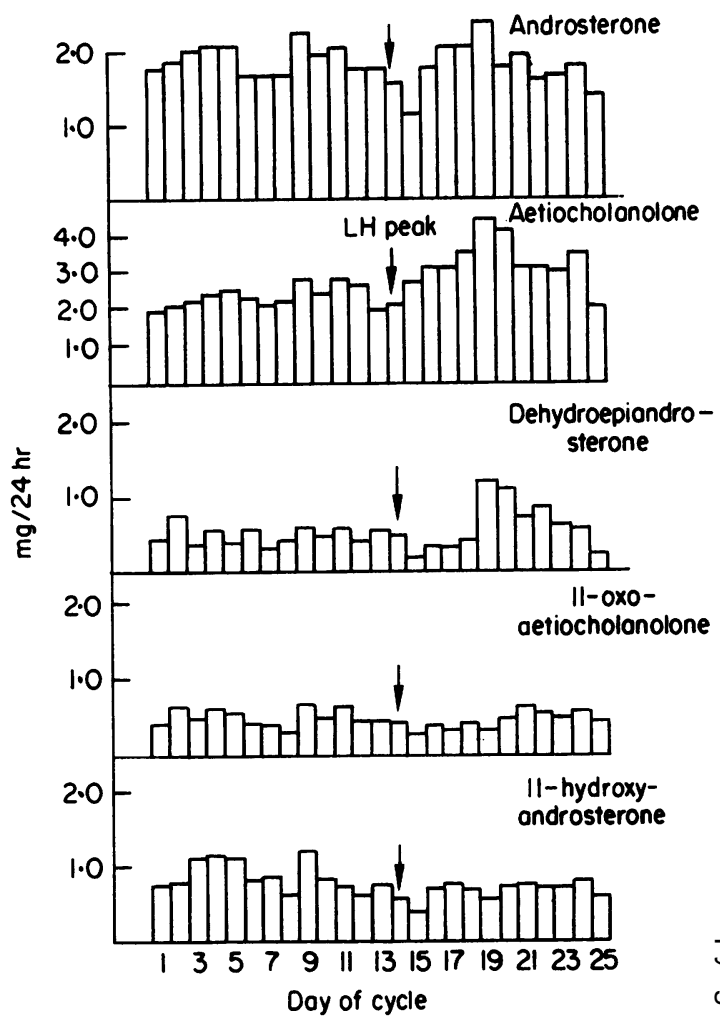

Fig. 8. The level of various $\mathrm{C}_{19}$-steroids throughout a complete menstrual cycle (cycle 1) determined by a high resolution gas-liquid chromatographic procedure.

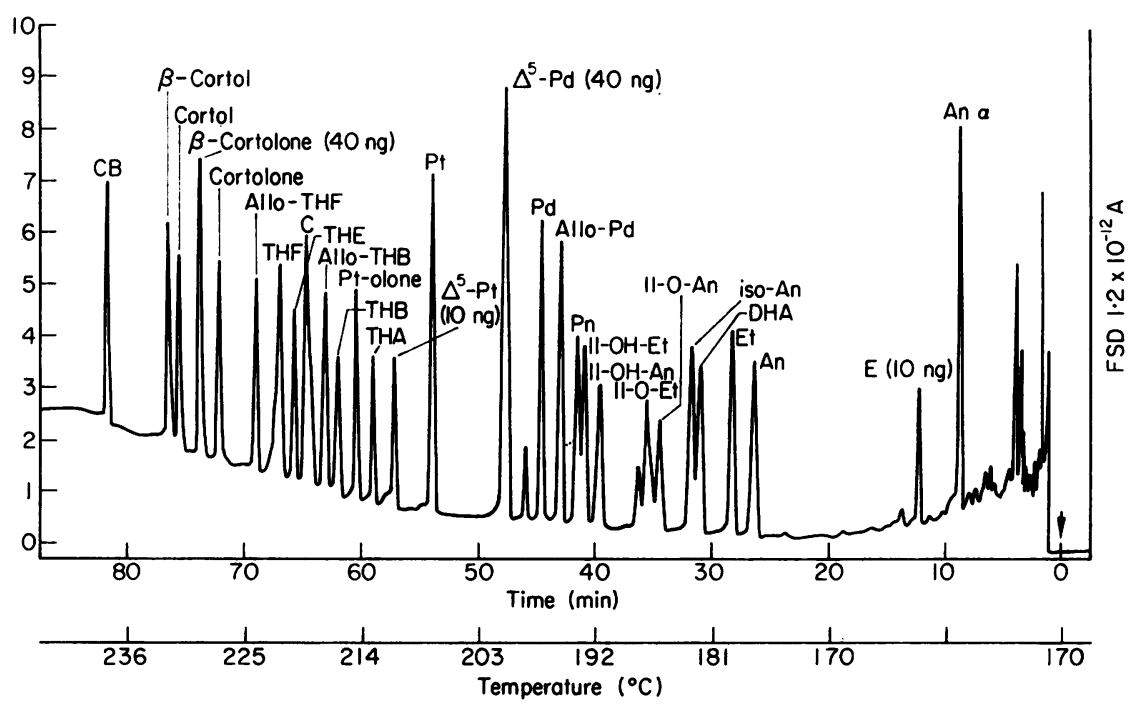

FIG. 7. The gas-liquid chromatographic separation of a standard mixture ( $20 \mathrm{ng}$ of each) of authentic steroids using a high resolution glass capillary column. 
Reference has already been made to the calculation of testosterone secretion rates and the practicability of such a technique in clinical assessment. The assay of testosterone and epitestosterone glucuronosides in urine has been applied to the investigation of hirsutism and menstrual disorders, for example, by Tucker, Bishop and Sommerville (1969). More recently, radioimmunoassay of plasma testosterone has been the assay of choice although other androgens, such as $5 \alpha$-dihydrotestosterone, are now being recognized as having at least equivalent importance (Mansfield and Johnson, 1974). The levels of testosterone, determined by the method of Collins et al. (1972), found in plasma from healthy women and those with certain pathological conditions are recorded in Table 2.

Indices of progesterone production can be summarized as follows: (1) $5 \beta$-pregnanediol and other metabolites in urine; (2) progesterone and $5 \beta$-pregnanediol in blood; (3) calculation of production rate; (4) $5 \alpha$-reductase activity in growth responsive tissues.

The first of these indices, the quantitative deter- mination of one of the urinary pregnanediols, is the time-honoured approach which has been used for many years, although it is still not clear how closely the excretion of this metabolite may reflect the endogenous level of production of the hormone. There is a characteristic rise in urinary pregnanediol excretion during the ovulatory menstrual cycle, although the extent to which this occurs is rather variable and the difference between levels in the follicular and luteal phase may not be very striking. That this rise is due to extra adrenal precursors was demonstrated by a study after bilateral adrenalectomy (Klopper, Strong and Cook, 1957). If pregnanediol assays are to be used instead of plasma progesterone assays then it is probable that the main field of application is in studying the effect of therapy-notably the induction of ovulation.

Recent advances have made possible the rapid and specific determination of progesterone in peripheral venous blood by radioimmunoassay and results obtained by Youssefnejadian et al. (1972) are shown in Table 3. Comparable values are obtained during the luteal phase of the menstrual cycle when the

TABLE 2. Plasma testosterone levels in healthy females and some endocrinological disturbances

\begin{tabular}{|c|c|c|c|}
\hline & \multirow{2}{*}{$\begin{array}{c}\text { No. of } \\
\text { determinations }\end{array}$} & \multicolumn{2}{|c|}{ Testosterone $\mathrm{ng} / 100 \mathrm{ml}$ plasma } \\
\hline & & Mean \pm s.d. & Range \\
\hline $\begin{array}{l}\text { Regular cycles, } \\
\text { no hirsutism }\end{array}$ & 46 & $49 \pm 16$ & $18-133$ \\
\hline $\begin{array}{l}\text { Regular cycles, } \\
\text { with hirsutism }\end{array}$ & 32 & $118 \pm 36$ & $47-184$ \\
\hline Oligomenorrhoea & 35 & $118 \pm 89$ & $23-345$ \\
\hline $2^{\circ}$ Amenorrhoea & 14 & $90 \pm 45$ & $41-143$ \\
\hline $\begin{array}{l}\text { Stein-Leventhal } \\
\text { syndrome }\end{array}$ & 20 & $135 \pm 60$ & $54-248$ \\
\hline Arrhenoblastoma & 2 & $561 \& 355$ & 一 \\
\hline
\end{tabular}

TABLE 3. Mean and range of values for plasma progesterone. Day 1 is defined as the first day of menses

\begin{tabular}{|c|c|c|c|}
\hline & \multirow{2}{*}{$\begin{array}{c}\text { No. of } \\
\text { determinations }\end{array}$} & \multicolumn{2}{|c|}{ Progesterone $\mathrm{ng} / 100 \mathrm{ml}$ plasma } \\
\hline & & Mean \pm s.d. & Range \\
\hline $\begin{array}{l}\text { Men } \\
20-40 \text { yrs }\end{array}$ & 72 & $23.0 \pm 6.8$ & $8-37$ \\
\hline $\begin{array}{l}\text { Women } \\
\text { days } 1-14\end{array}$ & 13 & $42 \cdot 4 \pm 18 \cdot 7$ & $24-79$ \\
\hline $\begin{array}{l}\text { Women } \\
\text { days } 15 \text {-end of } \\
\text { cycle }\end{array}$ & 12 & $770 \pm 190$ & $90-980$ \\
\hline $\begin{array}{l}\text { Women* } \\
\text { pregnant } \\
12 \text { weeks-term }\end{array}$ & 42 & $10.4 \pm 5.5$ & $4-23$ \\
\hline
\end{tabular}

* $\mu \mathrm{g} / 100 \mathrm{ml}$ plasma. 
method is performed with or without a chromatographic step and this provides a useful rapid method for the evaluation of luteal function. The difference between the progesterone concentration in the two phases of the menstrual cycle is much more dramatic than the corresponding values for the urinary metabolite and, in view of the simplicity of the technique (one technician can analyse twelve samples by the rapid method in $4 \mathrm{hr}$ ), plasma progesterone determinations are recommended in favour of urinary pregnanediol on both practical and theoretical grounds. Furthermore, it should be noted that no significant nycterohemeral variations in progesterone concentrations have been found in the peripheral venous blood of non-pregnant women.

This review has been mainly limited to attempts to assess the production of oestrogens, progesterone and testosterone and space does not permit a consideration of other steroids which may play an important role in human reproduction. A notable example is androstenedione where the secretion rate

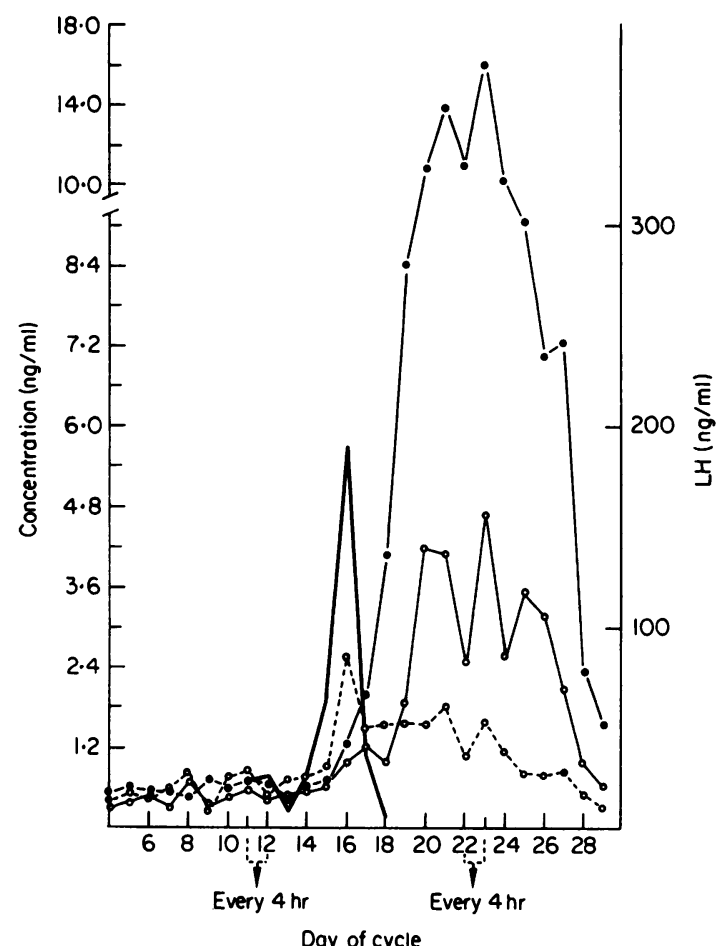

Fig. 9. Daily concentrations of progesterone (-O), 17-hydroxyprogesterone $(\bigcirc--\bigcirc)$ and 20a-dihydroprogesterone $(O-O)$ during a 'normal' menstrual cycle. $(\longrightarrow)=$ mid-cycle L.H. peak. in women is greater than in men. This steroid is of especial interest as it is a major precursor of oestrogen production in women and may be the principal source of oestrogens in the post-menopausal woman. In the Stein-Leventhal syndrome androstenedione levels are raised owing to reduced activity of the aromatization enzymes (Savard, Marsh and Rice, 1965). Another steroid of interest is 17-hydroxyprogesterone which may be assayed simultaneously with progesterone and 20 $\alpha$-dihydroprogesterone (Florensa et al., 1976). An example of the results obtained in ovulatory menstrual cycles is illustrated in Fig. 9.

In conclusion, recent advances in methodology offer the hope of new approaches to the study of ovarian function. It will be obvious from this paper that international research is still mainly concerned with the establishment of steroid concentrations in health and that systematic application to disease is largely a matter for the future.

\section{References}

Collins, W.P., Mansfield, M.D., Alladina, N.S. \& SOMMERVILlE, I.F. (1972) Radioimmunoassay of plasma testosterone. Journal of Steroid Biochemistry, 3, 333.

Emment, Y., Collins, W.P. \& Sommerville, I.F. (1972) Radioimmunoassay of oestrone and oestradiol in humano plasma. Acta endocrinologica, Copenhagen. 69, 567.

Florensa, E., Sommerville, I.F., Harrison, R.F., Johnson, M.W. \& Youssefnejadian, E. (1976) Plasma 20a-dihydroprogesterone, progesterone and 17-hydroxyprogesterone; daily and four-hourly variations during the menstrual cycle. Journal of Steroid Biochemistry (in press).

Klopper, A., Strong, J.A. \& Cook, L.R. (1957) The excretion of pregnanediol and adrenocortical activity. Journal of Endocrinology, 15, 180.

Mansfield, M.D. \& Johnson, M.W. (1974) The simultaneous determination of six $\mathrm{C} 19$ steroids in human peripheral plasma using a convenient radioimmunoassay technique. Journal of Steroid Biochemistry, 5, abstr. 41, 305.

Ros, A. \& Sommerville, I.F. (1971) Gas-liquid chromatography with high resolution glass capillary columns for the simultaneous determination of urinary steroids. Journal of Obstetrics and Gynaecology of the British Commonwealth, 78, 1096.

Savard, K., Marsh, J.M. \& Rice, B.F. (1965) Gonadotropins and ovarian steroido-genesis. Recent Progress in Hormone Research, 21, 285.

TAIT, J.F. \& HORTON R. (1966) The in vivo estimation of blood production and interconversion rates of androstenedione and testosterone and the calculation of their secretion rates. In: Steroid Dynamics (Ed. by G. Pincus, T. Nakao \& J. F. Tait), p. 393. Academic Press, New York.

TuCKER, E.C., Bishop, P.M.F. \& SOMMERville, I.F. (1969) Urinary testosterone and epitestosterone glucuronoside in hirsutism and certain menstrual disorders. Journal of Obstetrics and Gynaecology of the British Commonwealth, 76, 1111.

Youssefnejadian, E., Florensa, E., Collins, W.P. \& SOMMERVILLE, I.F. (1972) Radioimmunoassay of plasma progesterone. Journal of Steroid Biochemistry, 3, 893. 